\title{
EKSPLORASI Begonia spp (BEGONIACEAE) DI GUNUNG SIDOLE, KECAMATAN AMPIBABO, KABUPATEN PARIGI MOUTONG, SULAWESI TENGAH INDONESIA
}

\section{Ekploration Begonia spp (Begoniaceae) at Mount Sidole, Ampibabo District, Parigi Moutong Regency, Central Sulawesi Indonesia}

\author{
Eka Putri Dayanti dan Ramadanil \\ Jurusan Biologi Fakultas Matematika dan Ilmu Pengetahuan Alam Universitas Tadulako Tondo Palu, \\ Sulawesi Tengah 94118
}

\begin{abstract}
Keywords: The study entitled Exploration of Begonia (Begoniaceae) in the Sidole Begonia, exploration, Mount

Sidole, Central

Sulawesi Mountain, Ampibabo district, Parigi Moutong regency the province of Central Sulawesi has been conducted from December 2018 to April 2019. The objective of the research were to record and describe Begonia species from research site. The research by using botanical exploration methods. The results indicated that there were 4 (four) species of Begonia, namely B. aptera Blume, B.rieckei Warb., Begonia sp. 1 and Begonia sp. 2.

$\begin{array}{ll} & \text { ABSTRAK } \\ & \text { Penelitian yang berjudul Eksplorasi Begonia (Begoniaceae) di Gunung Sidole } \\ \text { Kata Kunci: } & \text { Kecamatan Ampibabo, Kabupaten Parigi Moutong, Sulawesi Tengah, Indonesia } \\ \text { Begonia, } & \text { telah dilakukan dari Bulan Desember } 2018 \text { hingga bulan April 2019. Penelitian } \\ \text { eksplorasi, } & \text { bertujuan untuk mencatat dan mendeskripsikan jenis-jenis Begonia yang } \\ \text { Gunung } & \text { berasal dari lokasi penelitian. Penelitian menggunakan metode eksplorasi } \\ \text { Sidole, } & \text { botani. Hasilnya menunjukan bahwa terdapat } 4 \text { jenis Begonia yaitu B. aptera } \\ \text { Sulawesi } & \text { Blume, B.rieckei Warb., Begonia sp. } 1 \text { and Begonia sp. } 2 .\end{array}$
\end{abstract}

“Corresponding Author : salukieka@yahoo.com

\section{PENDAHULUAN}

Begonia (Begoniaceae) salah satu marga terbesar dari tumbuhan berpembuluh yang tersebar di daerah pantropis dan saat ini telah mencapai 1896 jenis (Hughes et al., 2015). Begonia Sulawesi termasuk ke dalam tiga seksi yaitu Petermannia (Klotzsch) A. DC., Platycentrum (Klotzsch) A. DC. Dan Jackia M. Hughes (Moonlight et al., 2018). Tercatat saat ini 51 jenis Begonia berada di Sulawesi namun masih banyak yang belum teridentifikasi (Thomas et al., 2013).

Begonia Sulawesi termasuk dalam seksi Petermannia (Klotzsch) A. DC. memiliki ciri perbungaan betina terdiri satu atau sepasang, perbungaan jantan memiliki 2 tenda bunga dan bunga betina 5 tenda 
bunga, sayap berukuran sama, bakal buah berlokul tiga dan plasenta terbelah dua, Platycentrum (Klotzsch) A. DC. dua sayap pendek dan satu sangat panjang, terdapat sayap yang tumpul atau tidak berkembang, dan kepala sari memiliki konektor yang panjang, terdapat dua hingga tiga lokul pada bakal buah dan plasenta terbelah dua (Tebbitt, 2005) dan Jackia M. Hughes memiliki rimpang, tepal bunga jantan berjumlah 4 dan tepal betina berjumlah 3 (Moonlight et al., 2018).

Sulawesi saat ini menjadi pusat studi mengenai jenis-jenis Begonia namun masih banyak daerah yang belum terjelajahi, salah satunya Gunung Sidole. Gunung Sidole terletak di Kecamatan Ampibabo,

\section{BAHAN DAN METODE}

Penelitian ini dilakukan mulai bulan Desember 2018 hingga April 2019. Alat yang digunakan yaitu Global Position System (GPS) untuk pengambilan titik koordinat. Buku lapang untuk mencatatan data lapangan. Alat tulis untuk menulis. Meteran untuk pengukuran panjang dan lebar tumbuhan. Gunting stek untuk pengambilan sampel. Sasak untuk pengepresan spesimen. Botol spesimen untuk pengawetan basah buah dan bunga. Kamera untuk dokumentasi. Elektric stove untuk pengeringan spesimen. Bahan yang digunakan label gantung untuk pelabelan spesimen. Aluminium foil untuk
Kabupaten Parigi Moutong, Sulawesi Tengah, sampai saat ini belum ada laporan mengenai Begonia di daerah tersebut. Bagian Utara Gunung Sidole yaitu Gorontalo dan Sulawesi Utara telah tercatat penemuan B. cuneatifolia (Irmscher, 1914; Hughes, 2008) dan B. gemella (Smith and Wasshausen, 1983), sedangkan pada bagian Timur yaitu Gunung Katopas (Tojo Una-Una) dan Gunung Hek (Bunta) telah tercatat penemuan $B$. ozotothrix dan $B$. hekensis (Thomas et al., 2009a). Hal ini menjadi alasan penting mengapa harus dilakukannya pengoleksisan di Gunung Sidole, Kecamatan Ampibabo, Kabupaten Parigi Moutong, Sulawesi Tengah.

membungkus perakaran. Lumut untuk melembabkan perakaran. Plastik nener untuk menyimpan koleksi spesimen. Alkohol $70 \%$ untuk pengawetan spesimen. Koran untuk pembuatan hebarium. Amplop untuk pengoleksian biji atau benih. Kertas bebas asam untuk melakukan pemountingan spesimen.

\section{Prosedur Penelitian}

Pengoleksian Spesimen di Lapangan

Pengoleksian spesimen menggunakan metode jelajah (Rugayah et al., 2004). Jelajah dimulai dari kaki gunung Sidole di Desa Aloo dengan mengikuti jalur pendakian dan penyusuran sungai saat turun. Pengoleksian spesimen dengan 
melihat habitat yaitu permukaan tanah, permukaan batu, tebing dan dinding air terjun, sekaligus pengambilan data lapangan.

Spesimen yang dikoleksi merupakan tumbuhan fertil, sebanyak 3-5 duplikat dan telah di berikan label gantung yang berisi informasi nomor koleksi dan tanggal. Tumbuhan yang tidak fertil dilakukan pengoleksian hidup, bagian akar spesimen di bersihkan dari tanah, kemudian akar ditutup dengan lumut, setelah itu dibungkus menggunakan aluminium foil dan dimasukkan spesimen ke dalam plastik nener.

Pengawetan bagian generatif dengan 2 cara, yang pertama koleksi basah dengan merendam buah dan bunga kedalam botol spesimen yang telah berisi alkohol $70 \%$ (Rugayah et al., 2004) dan cara kedua koleksi kering untuk buah yang telah matang (benih) dengan memasukkan kedalam amplop.

\section{Pembuatan Spesimen Herbarium dan Identifikasi}

Proses pembuatan herbarium selanjutnya dilakukan di UPT. Sumber Daya Hayati (Herbarium CEB). Spesimen yang fertil yang telah dikoleksi di masukkan ke dalam oven listrik untuk proses pengeringan yang berlangsung selama 3-5 hari hingga kering merata, setelah spesimen kering dilanjutkan dengan pembuatan spesimen herbarium. Pembuatan spesimen herbarium menurut
Simpson (2006), spesimen kering ditempelkan diatas kertas bebas asam dengan merekatkan label herbarium di sudut kanan bawah spesimen yang mencantumkan karakter spesimen pada paragraf pertama dan paragraf kedua mengenai habitat dan asal spesimen. Identifikasi spesimen mengacu pada jurnal taxonomi Begonia (Hughes, 2006, Girmansyah et al., 2009, Thomas et al., 2009a, Thomas et al., 2009b, Thomas et al., 2011, Wiriadinata, 2013, Ardi et al., 2014, Lin et al., 2017, Thomas et al., 2018, dan Ardi et al., 2018) dan website Sulawesi Begonia Data Portal "http://portal.cybertaxonomy.org/floramalesianaporspective/".

\section{HASIL DAN PEMBAHASAN}

\section{Hasil}

Gunung Sidole memiliki ketinggian 1900 m dpl dan terdapat 3 tipe habitat yaitu Agroforestry, hutan sekunder dan hutan primer. Berdasarkan hasil identifikasi Begonia di Gunung Sidole terdapat 4 jenis dari 7 individu yang didapatkan, masingmasing memiliki karakter morfologi yang berbeda-beda yaitu $B$. aptera Blume, $B$. rieckei Warb., Begonia sp.1 dan Begonia sp.2. Seksi dari keempat jenis termasuk kedalam Petermannia (Klotzsch) A. DC. yaitu B. rieckei Warb., Begonia sp.1 dan Begonia sp.2 sedangkan B. aptera Blume termasuk kedalam Platycentrum (Klotzsch) A. DC. Keempat jenis hanya dijumpai pada 
2 tipe habitat yaitu hutan sekunder ( $B$. rieckei dan Begonia sp.1) dan hutan primer (B. aptera dan Begonia sp.2) (Tabel 1. Perbandingan karakter morfologi).

\section{Deskripsi Begonia}

1. Begonia aptera Blume (Blume (1827:97) (Sect. Platycentrum)
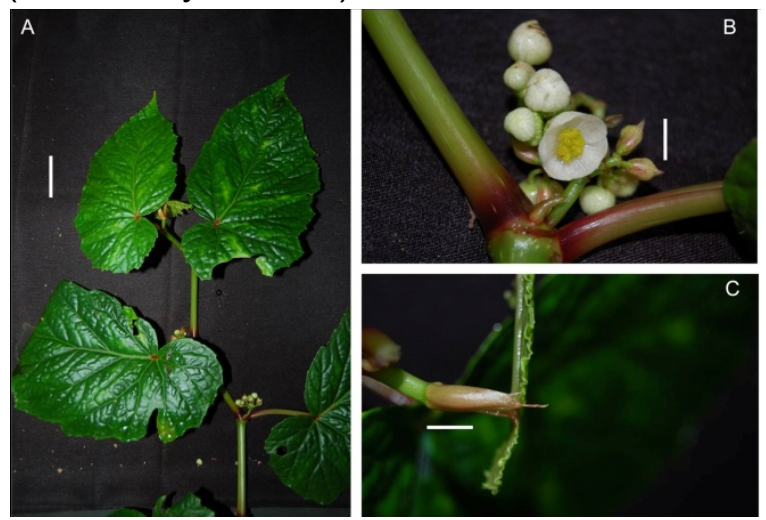

Gambar 2. Begonia aptera. A. Daun, skala: 2 $\mathrm{cm}$. B. Perbungaan, skala: $3 \mathrm{~mm}$. C. Stipul, skala: $5 \mathrm{~mm}$. Foto: Eka Putri Dayanti, 2019.

Deskripsi: berumah satu, tegak, panjang hingga $2 \mathrm{~m}$. Batang berdaging, hijau, tanpa rambut, diameter $4-12 \mathrm{~mm}$, ruas 7-18 cm. Daun: penumpu luruh, membundar telur hingga lanset, 0.8-2 $\times$ 0.2-0.45 cm, ujung meruncing hingga melancip; tangkai 12.5-16.5 cm, diameter 1-3 mm, tidak berambut; helaian daun berwarna hijau pada kedua sisi, tidak berambut, asimetris, ellips, 10$22 \times 4-14 \mathrm{~cm}$, ujung meruncing hingga melancip, dasar menjantung, tumpang tindih, tepi bergigi ganda; pertulangan menjari. Perbungaan protandrous, menyatu, dichasium, 2-3 cabang, hingga
20 bunga, bunga jantan dan bunga betina dalam satu perbungaan; tangkai perbungaan ca. $10 \mathrm{~mm}$, tidak berambut; tangkai bunga jantan 6-7 $\mathrm{mm}$, bunga betina ca. $5 \mathrm{~mm}$; penumpu perbungaan luruh, membundar telur, 4-6 × $2.5 \mathrm{~mm}$; penumpu tangkai bunga tidak ada. Bunga jantan tenda putih, tenda 4 , bagian luar tenda $4-8 \times 2.8-4.2 \mathrm{~mm}$, bagian dalam tenda 3-8.5 × 2.8-4.2 mm, membundar telur hingga jorong, ujung membulat; benang sari 25-50, tangkai sari 1-1.5 mm, terpusat didasar, kepala sari 1.5-2 $\mathrm{mm}$, terkoneksi diujung, ujung membulat. Bunga betina: tenda 6, 3.1$10 \times 2.2-6 \mathrm{~mm}$, putih, membundar telur hingga jorong; bakal buah berdaging hampir bulat, sayap tumpul, lokul 3 , plasenta terpecah, tangkai putik 3 , luruh, 2.4-4 mm, menyatu pada dasar, satu atau dua putaran spiral. Buah: 1-10 buah; tangkai $0.5-1 \mathrm{~cm}$; buah berdaging, hijau hingga merah, hampir bulat, $1 \times 1.2$ $\mathrm{cm}$, tidak berambut.

Habitat dan ekologi: spesimen ini dikoleksi pada jalur pendakian dengan ketinggian ca. 1100-1800 m dpl (LS 00³1'55.05", BT 11958'17.01"), Desa Aloo, Sulawesi Tengah, 26 Desember 2018. 


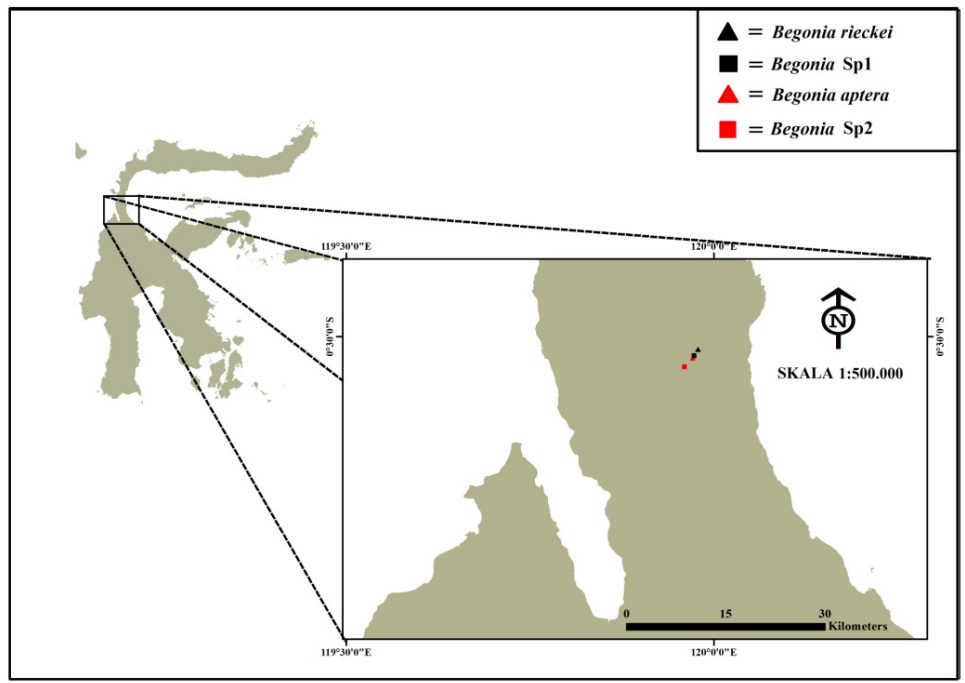

Gambar 1. Peta lokasi pengoleksian

Tabel 1.Perbandingan karakter morfologi.

\begin{tabular}{|c|c|c|c|c|}
\hline \multirow{2}{*}{ Karakter } & \multicolumn{4}{|c|}{ Spesies } \\
\hline & B. aptera & B. rieckei & Begonia sp.1 & Begonia sp.2 \\
\hline Helaian daun & $10-22 \times 4-14 \mathrm{~cm}$, jorong & $\begin{array}{l}10-20 \times 7-14 \mathrm{~cm} \text {, } \\
\text { membundar telur }\end{array}$ & $4-8 \times 1-2.7 \mathrm{~cm}$, jorong & $\begin{array}{l}2.5-4.7 \times 1.5-2.8 \\
\mathrm{~cm}, \text { membundar } \\
\text { telurhinggajorong }\end{array}$ \\
\hline Perbungaan & $\begin{array}{l}\text { Protandrous, menyatu (bunga } \\
\text { jantan dan bunga betina) }\end{array}$ & $\begin{array}{l}\text { Protogynous, menyatu } \\
\text { (bunga jantan dan bunga } \\
\text { betina) }\end{array}$ & $\begin{array}{l}\text { Protogynous, terpisah } \\
\text { (bunga jantan dan } \\
\text { bunga betina) }\end{array}$ & $\begin{array}{l}\text { Protogynous, terpisah } \\
\text { (bunga jantan dan } \\
\text { bunga betina) }\end{array}$ \\
\hline Bunga jantan & $\begin{array}{l}4-8 \times 2.8-4.2 \text {, membundar } \\
\text { telur hinggajorong }\end{array}$ & $\begin{array}{l}5-10 \times 4-12 \mathrm{~mm} \text {, } \\
\text { bundarhinggajorong }\end{array}$ & $\begin{array}{l}5-6 \times 6-7 \mathrm{~mm} \text {, agak } \\
\text { bundar }\end{array}$ & $\begin{array}{l}11-13 \times 14-15 \mathrm{~mm} \text {, } \\
\text { membundar } \\
\text { telurhinggaagak bundar }\end{array}$ \\
\hline Androecium & ca. $25-50$ benang sari & ca. $20-60$ benang sari & ca. $21-25$ benang sari & ca. $36-40$ benang sari \\
\hline Bunga betina & $\begin{array}{l}3.1-10 \times 2.2-6 \mathrm{~mm} \text {, } \\
\text { membundar telur hingga } \\
\text { jorong }\end{array}$ & $\begin{array}{l}6-12 \times 3.75-7 \mathrm{~mm} \text {, bundar } \\
\text { hingga jorong }\end{array}$ & $\begin{array}{l}\text { ca. } 4 \times 2 \mathrm{~mm} \text { (kecil), } \\
\text { membundar telur } \\
\text { sungsang, } 7-9 \times 4.5-5 \\
\text { mm (besar), } \\
\text { membundar telur }\end{array}$ & $\begin{array}{l}7-9 \times 4.5-7.5 \mathrm{~mm} \\
\text { (kecil), } 8-12.5 \times 5-12 \\
\mathrm{~mm}(\text { besar), membundar } \\
\text { telur }\end{array}$ \\
\hline Bakal buah & ca. $5 \times 6.5 \mathrm{~mm}$ & $6-12 \times 7-12 \mathrm{~mm}$ & ca. $7 \times 3 \mathrm{~mm}$ & $6-8 \times 4-5 \mathrm{~mm}$ \\
\hline Buah & ca. $1 \times 1.2 \mathrm{~cm}$ & $9-11 \times 12-15 \mathrm{~mm}$ & $4.5-6 \times 3.5-4 \mathrm{~mm}$ & $8-10 \times 5-6 \mathrm{~mm}$ \\
\hline
\end{tabular}

Catatan: Begonia aptera tersebar luas dikawasan Malesia Timur (Ardi et al., 2018), jenis ini ditemukan pada hutan sekunder hingga hutan primer. B. aptera termasuk ke dalam seksi Platycentrum dengan memiliki 3 lokul dengan sayap yang tumpul atau tidak berkembang, jenis ini memiliki morfologi sangat bervariasi seperti memiliki rambut yang menutupi seluruh bagian batang hingga buah dan tidak memiliki rambut. 
2. Begonia rieckei Warb. (1891:397) (Sect. Petermannia)

3.

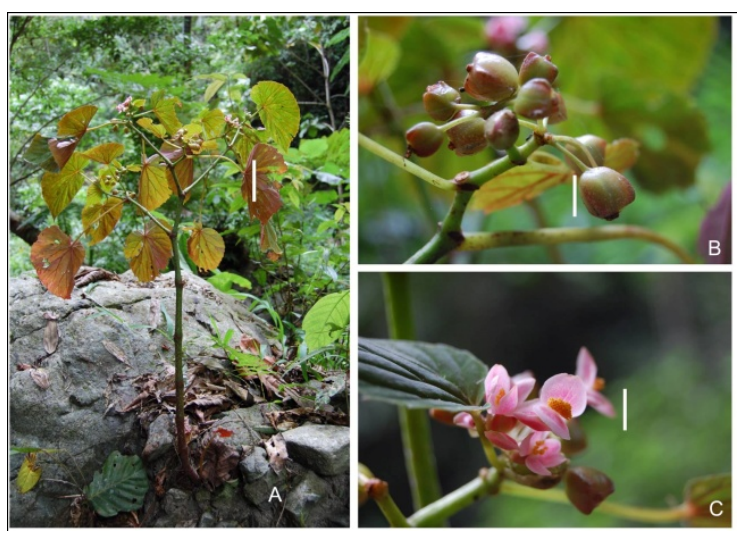

Gambar 3. Begonia rieckei.A. Habit, skala: 10 cm. B. Buah, skala: $9 \mathrm{~mm}$. C. Perbungaan, skala: $6 \mathrm{~mm}$. Foto: Eka Putri Dayanti, 2019.

Deskripsi: berumah satu, tegak, tinggi hingga $1 \mathrm{~m}$, batang hijau hingga kemerahan, bengkak pada ruas. Daun berseling; stipul luruh, membundar telur hingga lanset; tangkai daun hijau hingga kemerahan, ca. $23 \mathrm{~cm}$; helaian daun tipis, membundar telur, 10-20 × 7-14 $\mathrm{cm}$, ujung meruncing, dasar sangat asimetris, menjantung, tepi bergigi, permukaan atas hijau terang, permukaan bawah hijau pucat; pertulangan menjari, kemerahan. Perbungaan protogynous, menyatu, terminal, tandan, tangkai 2.5 $\mathrm{cm}$; bunga betina 2-12, bunga jantan 5 25; daun penumpuh perbungaan luruh, membundar telur. Bunga jantan tenda 2, bundar hingga jorong, merah muda, 5$10 \times 4-12 \mathrm{~mm}$; benang sari 20-60, kepala sari jorong hingga lonjong, ca. 1.5 $\mathrm{mm}$, ujung membulat tidak terkoneksi.
Bunga betina tenda 5, merah muda, 2 bagian luar tenda, bundar hingga jorong, 6-12 × 3.75-7 mm, 3 bagian dalam tenda, jorong, 6-9 × 2.25-4 mm; bakal buah putih hingga hijau, berair, jorong, 6-12 ×7-12, bersayap 3, 3 lokul; tangkai putik luruh, ca. 3-4 mm, terpusat di dasar, terbelah, stigma spiral. Buah 112, tangkai ca. $2.5 \mathrm{~cm}, 9-11 \times 12-15$ $\mathrm{mm}$.
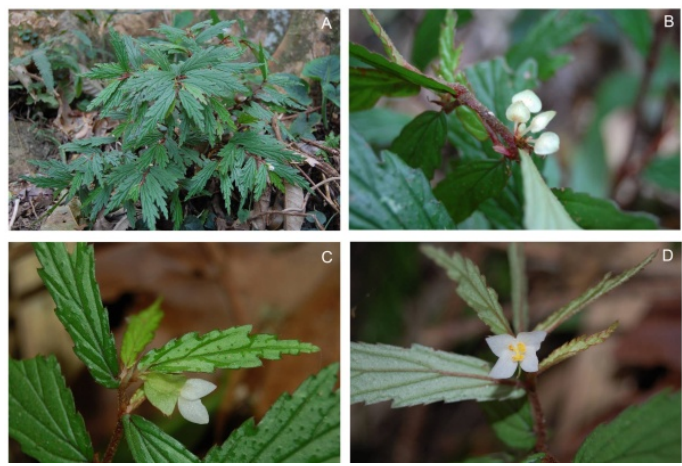

Gambar 4. Begonia sp.1 A. Habit, skala: 10 $\mathrm{cm}$. B. Perbungan jantan, skala: 7 $\mathrm{mm}$. C. Buah, skala: $5 \mathrm{~mm}$. D. Bunga betina, skala: $10 \mathrm{~mm}$. Foto: Eka Putri Dayanti, 2019.

Habitat dan ekologi: spesimen ini dikoleksi pada pinggiran sungai, hidup diatas permukaan batu pada ketinggian ca. $610 \mathrm{~m}$ dpl (LS 00³1'14.47", BT 11958'42.17"), Desa Aloo, Sulawesi Tengah, 29 Desember 2018.

Catatan: Begonia rieckei termasuk kedalam seksi Petermannia dan tersebar luas seperti B.aptera. jenis ini terdapat pada hutan sekunder dan hidup pada permukaan batu. 


\section{Begonia sp.1 (Sect. Petermannia)}

Diagnosa: jenis ini hampir menyerupai dengan Begonia cuneatifolia Irmsch. (370:1913), tetapi perbedaan dengan jenis ini yaitu daun jorong, helaian daun kaku, berambut pada kedua sisi, tepi bergerigi ganda, dasar tidak setara, stipul lanset dan memiliki benang sari ca. 2125. Sedangkan Begonia cuneatifolia memiliki daun membundar telur sungsang hingga membundar telur, helaian daun tipis, tidak berambut, tepi rata, dasar mengerucut, stipul lonjong hingga lanset dan memiliki benang sari ca. 40 .

Deskripsi: perennial, berumah satu, tegak dengan tinggi ca. $35 \mathrm{~cm}$. Batang bercabang, ruas $2-5 \mathrm{~cm}$, merah kecoklatan dengan rambut yang padat. Daun berseling; stipul tidak luruh, 7-10 $\times$ 3-4 mm, lanset, merah, permukaan bawah licin, pertulangan menonjol, pinggiran rata, ujung menyempit menjadi rambut hingga $1 \mathrm{~mm}$; tangkai $5-6 \mathrm{~mm}$, merah kecoklatan, berambut; helaian daun 4-8 x 1-2.7 cm, asimetris, hampir jorong, ujung melancip, dasar tidak setara, tidak tumpang tindih, tepi bergerigi ganda, permukaan atas hijau, dengan rambut jarang di antara pertulangan, permukaan bawah hijau pucat, berambut pada pertulangan; pertulangan berseling. Perbungaan protogynous, terpisah; perbungaan betina dengan 1 bunga, soliter atau berbeda satu nodus dari jantan; perbungaan jantan paniculate, tersusun hingga tiga monokasial sederhana yang terkompresi; tangkai perbungaan ca. 1 $\mathrm{mm}$, berambut; penumpu perbungaan ca. $8 \times 3 \mathrm{~mm}$, lanset, bening, midrib merah, permukaan bawah licin, tepi rata, apex meruncing, tidak luruh; penumpu bunga ca. 2-3× $1 \mathrm{~mm}$, lanset, bening, pertulangan merah, tidak luruh. Bunga jantan tangkai bunga 4-5 mm, putih; tenda 2, agak bundar, 5-6 × 6-7 mm, putih, permukaan bawah berambut jarang, tepi rata, ujung membulat; benang sari ca. 21-25, kuning, tangkai sari hingga ca. $1-1.5 \mathrm{~mm}$, terpusat di dasar, kepala sari ca. 0.5-1 mm. Bunga betina tangkai bunga $3-4 \mathrm{~mm}$, putih; tenda 5, putih, satu kecil dengan ukuran ca. $4 \times 2 \mathrm{~mm}$, membundar telur sungsang, empat besar dengan ukuran 7-9 × 4.5-5 mm, membundar telur, ujung meruncing, tepi rata; bakal buah (tanpa sayap) hijau pucat, ca. $7 \times 3 \mathrm{~mm}$, menjorong, lokul 3, plasenta terbelah, sayap 3, dasar membulat, ujung rata, bagian terlebar hingga $4 \mathrm{~mm}$; tangkai putik ca. 0.5-1 $\mathrm{mm}$, terpusat di dasar, bercabang 3 , stilodium bercabang dua pada bagian stigma, stigma spiral, 
jingga. Buah tangkai perbuahan ca. 2.5$3 \mathrm{~mm}$; tangkai buah ca. $0.5 \mathrm{~mm}$; $4.5-6 \times$ 3.5-4 mm (tanpa sayap), bagian terlebar ca. $5 \mathrm{~mm}$. Biji ca. $0.2-0.3 \mathrm{~mm}$.

Habitat dan ekologi: spesimen ini dikoleksi pada jalur pendakian gunung Sidole ketinggian ca. $930 \mathrm{~m} \mathrm{dpl}$ (LS 00³1'42.75", BT $\left.119^{\circ} 58^{\prime} 23.09^{\prime \prime}\right)$, Desa Aloo, Sulawesi Tengah, 26 Desember 2018.

Catatan: Begonia sp.1 termasuk kedalam seksi Petermannia. Begonia sp.1 menyerupai dengan $B$. cuneatifolia yang berasal dari Gorontalo dan Sulawesi Utara, namun jenis ini pada permukaan batang ditutupi rambut kaku yang padat, helaian daun kaku, tepi bergerigi ganda dan bunga jantan berjumlah 3 sedangkan $B$. cuneatifolia batang tidak berambut, helaian daun tipis, tepi rata dan bunga jantan berjumlah 5-8. Karakter morfologi keduanya dapat membedakan bahwa Begonia sp.1 dan B. cuneatifolia adalah jenis berbeda.

\section{Begonia sp.2 (Sect. Petermannia)}

Diagnosa: jenis ini hampir menyerupai Begonia gemella Warb. ex L.B.Sm. \& Wassh. (443:1983), tetapi perbedaan jenis ini terlihat dari daun berbentuk membundar telur hingga jorong, tepi bergigi hingga bergerigi ganda, sangat asimetris, stipul ca. 4-5 × 2-3 mm, tangkai 5-20 mm, bunga jantan memiliki 2 tenda dan bunga betina memiliki 5 tenda. Sedangkan Begonia gemella memiliki berbentuk agak bundar, tepi bergigi, stipul ca. 7-8 $\times$ 3-4, tangkai 1$3.6 \mathrm{~cm}$, bunga jantan memiliki 2 tenda dan bunga betina memiliki 2 tenda.

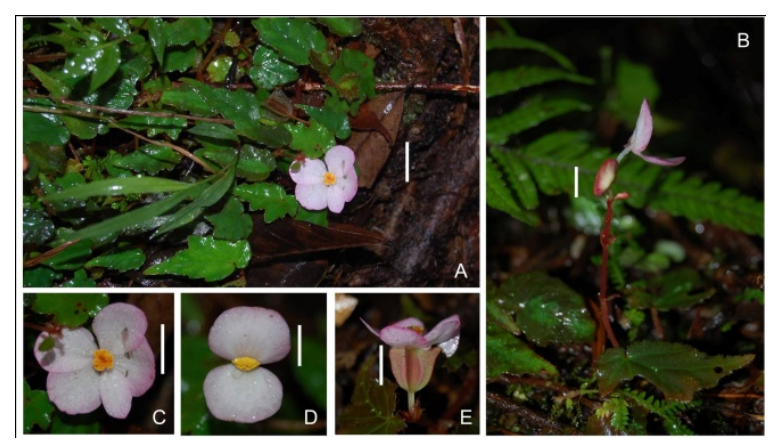

Gambar 5. Begonia sp.2. A. Habit, skala: $8 \mathrm{~mm}$. B. Perbungaan, skala: $5 \mathrm{~mm}$. C. Bunga Betina, skala: $8 \mathrm{~mm}$. D. Bunga Jantan,skala: $10 \mathrm{~mm}$. E. Buah; skala: $8 \mathrm{~mm}$.

Deskripsi: perenial, berumah satu, tingga hingga $10 \mathrm{~cm}$, merayap, ruas berakar ketika bensentuhan pada substrat. Batang bercabang, ruas 1-3 $\mathrm{cm}$, kemerahan-kecoklatan. Daun berseling; stipul tidak luruh, jorong, ca. 4-5 × 2-3 mm, kemerahan, bening, pertulangan sedikit menonjol, tepi rata, ujung melancip dengan rambut (ca. 2 $\mathrm{mm}$ ); tangkai 5-20 mm, kemerahan, rambut jarang; helaian daun basifixed, $2.5-4.7 \times 1.5-2.8 \mathrm{~cm}$, membundar telur hingga jorong, sangat simetris, dasar menjantung, terkadang sedikit tumpang 
tindih, ujung melancip, tepi bergerigi hingga bergerigi ganda, bagian tepi berambut, permukaan atas hijau kemerahan dengan bercak keperakan pada pertulangan, licin hingga sedikit berambut antara pertulangan, permukaan bawah hijau pucat, berambut. Perbungaan protogynous, terpisah; perbungaan betina dengan satu bunga, soliter atau berbeda satu nodus dengan jantan, tangkai perbungaan 1.5 $\mathrm{mm}$, merah, licin; perbungaan jantan terdiri hingga 3 cabang utama perbungaan tersusun dalam monokasial sederhana terkompresi dengan 2-3 bunga, tangkai perbungaan ca $2.5 \mathrm{~mm}$, merah, licin; penumpu perbungaan seperti stipul, tidak luruh, 4-5 × 2-3 mm, dengan rambut $1.5 \mathrm{~mm}$. Bunga jantan tangkai 13-16 mm, merah muda, licin; tenda 2, bulat telur hingga agak bundar, $11-13 \times 14-15 \mathrm{~mm}$, merah muda pucat, permukaan atas licin, tepi rata, ujung membulat; androsium kuning, benang sari $36-40$, tangkai sari bebas hingga 0.3-0.6 mm, terpusat di dasar, kepala sari hingga $0.5-1 \mathrm{~mm}$. Bunga betina tangkai 5-7 mm, licin, kemerahan; tepal 5 , putih kemerah mudaan, satu kecil 7-9 $\times 4.5-7.5 \mathrm{~mm}$, empat besar 8-12.5 × 5$12 \mathrm{~mm}$, keseluruhan membundar telur, tepi rata, permukaan licin; bakal buah (tanpa sayap) 6-8 × 4-5 mm, menjorong, licin, kuning, lokul 3 , plasenta terbelah, sayap 3 , dasar membulat, ujung rata hingga hampir rata, titik terlebar $6-8 \mathrm{~mm}$, tangkai putik ca. 2.5 $\mathrm{mm}$, terpusat di dasar, bercabang 3 , stilodium bercabang dua pada bagian putik, putik spiral, jingga. Buah tangkai 7-8 mm, 8-10 × 5-6 mm (tanpa sayap) menjorong, sayap sama dengan bakal buah, titik terlebar 2.5-3 mm. Benih ca. $0.3 \mathrm{~mm}$.

Habitat dan ekologi: spesimen ini dikoleksi di daerah sekitaran puncak gunung Sidole ketinggian ca. 1700-1900 $m$ dpl (LS 00³2'32.84", BT $119^{\circ} 57^{\prime} 33.33^{\prime \prime)}$, Desa Aloo, Sulawesi Tengah, 27 Desember 2018.

Catatan: Begonia sp.2 merupakan tumbuhan merayap yang termasuk kedalam seksi Petermannia. Jenis Begonia Sulawesi lainnya yang memiliki habit merayap yaitu $B$. gemella, $B$. flacca, B. matarombeoensis dan $B$. heteroclinis, dari keempat jenis ini $B$. gemella yang hampir mendekati karakter Begonia sp.2. Perbedaan dari kedua jenis ini yaitu Begonia sp.2 memiliki daun berbentuk membundar telur hingga jorong dengan sedikit rambut pada permukaan, sangat asimetris, jumlah tenda bunga betina 5 , sedangkan $B$. gemella memiliki bentuk daun agak bundar, jumlah tenda bunga betina 2 . 


\section{Simpulan}

Hasil penelitian ini dapat disimpulkan bahwa Gunung Sidole ditemukan 4 jenis yaitu $B$. aptera Blume, B.rieckei Warb., Begonia sp. 1 dan Begonia sp.2 yang terdapat pada hutan sekunder dan hutan primer.

\section{UCAPAN TERIMA KASIH}

Ucapan terima kasih pertama penulis berikan kepada Dra. Hartutiningsih Siregar, M.Si dan Wisnu Handoyo Ardi (Kebun Raya Bogor) yang telah membimbing penulis dalam melakukan identifikasi Begonia. Terima kasih juga penulis tujukan kepada Roland Putra Pribadi Ahmad, Zulfadli, Moh. Iqbal, Rahmat Adryan dan Rifki Kurniawan yang telah membantu dalam proses pengambilan sampel di Gunung Sidole.

\section{DAFTAR PUSTAKA}

Ardi, W. H., Ardaka, I. M., Hartutiningsih, Lugrayasa, I. N., and Thomas, D. C. 2014. Two new spesies of Begonia (Begoniaceae) from Sulawesi, Indonesia. Edinburgh Journal Of Botany, 71(2), 259-268.

Ardi, W. H., Chikmawati, T., Witono, J. R., and Thomas, D. C. 2018. A synopsis of Begonia (Begoniaceae) of Southeastern Sulawesi including four new spesies. Phytotaxa, 381(1), 027050.

Girmansyah, D., Wiriadinata, H., Thomas, D. C., and Hoover, W. S. 2009. Two new spesies and one new subspecies of Begonia (Begoniaceae) from Southeast
Sulawesi, Sulawesi, Indonesia. REINWARDTIA, 13(1), 69-74.

Hughes, M. 2006. Four new species of Begonia (Begoniaceae) from Sulawei. Edinburgh Journal Of Botany, 63(2\&3), 191-199.

Hughes, M. 2008. An annotated checklist of Southeast Asian Begonia. UK: Royal Botanic Garden Edinburgh.

Hughes, M., Moonlight, P. W., Jara, A., Tebbitt, M. C., Wilson, H. P., and Pullan, M. 2015. Begonia Resource Center. Online database available from

http://padme.rgbe.org.uk/begonia/.

Irmscher, E. 1941. Nue Begoniaceae papuasiens mit einschlufs von Celebes. In Engler, A. (Ed.), Botanische Jahrbücher für Sytematik, Pflanzengeschichte und Pflanzengeographie (pp. 443).

Lin, C. W., Thomas, D. C., Ardi, W. H., and Peng, C. I. 2017. Begonia ignita (Sect.Petermannia, Begoniaceae) a new species with orange flowers from Sulawesi, Indonesia. Gardens' Bulletin Singapore, 69(1), 89-95.

Moonlight, P. W., Wisnu, H. A., Padilla, L. A., Chung, K. F.., Fuller, D., Girmansyah, D., Hollands, R., Jara, A. M., Kiew, R., Leong, Wai, C., Liu, Y., Mahardika, A., Marasinghe, L. D. K., O'connor, M., Peng, C. I., Perez, A. J., Phutthai, T., Pullan, M., Rajbhandary, S., Reynel, C., Rubite, R. R., Sang, J., Scherberich, D., Shui, Y. M., Tebbitt, M. C., Thomas, D. C., Wilson, H. P., Zaini, N. H., and Hughes, M. 2018. Dividing and conquering the fastestgrowing genus: Towards a natural sectional classification of the mega- 
diverse genus Begonia (Begoniaceae). Taxon, 67(2), 267323.

Rugayah., Retnowati, A., Windadri, F. I., dan Hidayat, A. 2004. Pengumpulan data taksonomi. Di dalam Rugayah, Widjaja E. A., Praptiwi, (Ed.). Pedoman Pengumpulan Data Keanekaragaman Flora. Bogor (ID): Puslit-LIPI.

Simpson, M. G. 2006. Plant systematic: chapter 18 herbaria and data information system. USA: Library of Congress Cataloging in Publication Data.

Smith, L. B., and Wasshausen, D. C. 1983. Notes on Begoniaceae. Phytologia, 52(7), 443.

Thomas, D. C., Ardi, W. H., and Hughes, M. 2009a. Two new species of Begonia (Begoniaceae) from Central Sulawesi, Indonesia. Edinburgh Journal Of Botani, 66(1), 103-114.

Thomas, D. C., Ardi, W. H., Hartutiningsih, and Hughes, M. 2009b. Two new species of Begonia (Begoniaceae) from South Sulawesi, Indonesia. Edinburgh Journal Of Botani, 66(2), 229-238.

Thomas, D. C., Ardi, W. H., and Hughes, M. 2011. Nine new species of Begonia (Begoniaceae) from South and West Sulawesi, Indonesia. Edinburgh Journal Of Botany, 68(2), 225-255.

Thomas, D. C. Bour, A., and Ardi, W. H. 2018. Begonia of the Matarombeo karst, Southeast Sulawesi, Indonesia, including two new species. Gerden's Bulletin Singapore, 70(1), 163-176.

Thomas, D. C., Ardi, W. H., Girmansyah, D., and Hughes, M. 2013. Continuously update. Sulawesi Begonia Data Portal. Electronic resource. http://portal.cybertaxonomy.org/floramalesiana-porspectivel.

Wiriadinata, H. 2013. A new species of Begonia (Begoniaceae) from south Sulawesi, Indonesia. REINWARDTIA, 13(5), 445-448. 
Dayanti dan Ramadanil. Biocelebes. Desember. 2020. Vol. 14 No. 3, 217-228 